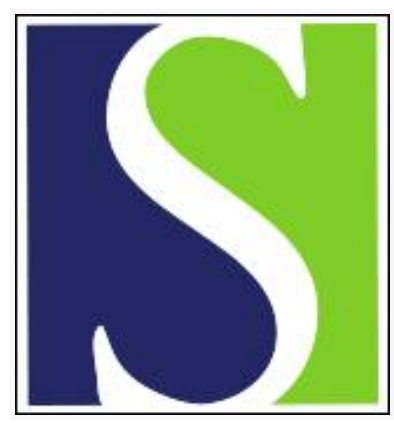

Scand J Work Environ Health 2017;43(3):287-288

https://doi.org/10.5271/sjweh.3630

Published online: 15 Mar 2017, Issue date: 01 May 2017

\title{
Ocular ultraviolet radiation exposure of welders
}

by Tenkate TD

This letter disputes the conclusion of Slagor et al that there are no studies of ocular ultraviolet radiation (UVR) exposure of welders. Using published results, a comparison with the UVR exposure of outdoor workers is provided.

Affiliation: Ryerson University, 350 Victoria Street, Toronto, Ontario, M5B 2K3 Canada. [E-mail: thomas.tenkate@ryerson.ca]

Refers to the following text of the Journal: 2016;42(5):447-453

Key terms: exposure; letter; ocular ultraviolet radiation; ultraviolet radiation; UVR; welder

This article in PubMed: www.ncbi.nlm.nih.gov/pubmed/28295119 


\section{Ocular ultraviolet radiation exposure of welders}

I read with interest a recent paper in your journal by Slagor et al on the risk of cataract in relation to metal arc welding (1). The authors highlight that even though welders are exposed to substantial levels of ultraviolet radiation (UVR), "no studies have reported data on how much UVR welders' eyes are exposed to during a working day." (1, p451).

Undertaking accurate exposure assessment of UVR from welding arcs is difficult, however, two studies have reported ocular/facial UVR levels underneath welding helmets $(2,3)$. In the first paper, UVR levels were measured using polysulphone film dosimeters applied to the cheeks of a patient who suffered from severe facial dermatitis (2). UVR levels of four times the American Conference of Governmental Industrial Hygienists (ACGIH) maximum permissible exposure (MPE) (4) were measured on the workers left cheek and nine times the MPE on the right cheek. The authors concluded that the workers dermatitis was likely to have been due to the UVR exposure received during welding.

In the other paper, a comprehensive exposure assessment of personal UVR exposure of workers in a welding environment was reported (3). The study was conducted at a metal fabrication workshop with participants being welders, boilermakers and non-welders (eg, supervisors, fitters, machinists). Polysulphone film dosimeters were again used to measure UVR exposure of the workers, with badges worn on the clothing of workers (in the chest area), on the exterior of welding helmets, attached to 11 locations on the inside of welding helmets, and on the bridge and side-shields of safety spectacles. Dosimeters were also attached to surfaces throughout the workshop to measure ambient UVR levels. For welding subjects, mean 8-hour UVR doses within the welding helmets ranged from around $9 \mathrm{~mJ} / \mathrm{cm}^{2}(3 \times \mathrm{MPE})$ on the inside of the helmets to around $15 \mathrm{~mJ} / \mathrm{cm}^{2}(5 \times \mathrm{MPE})$ on the headband (a location to approximate ocular exposure). UVR exposures for non-welding workers were also quite substantial, with mean 8-hour doses on the outside of safety spectacles being around $36 \mathrm{~mJ} / \mathrm{cm}^{2}(12 \times \mathrm{MPE})$ on the bridge and around $27 \mathrm{~mJ} / \mathrm{cm}^{2}(9 \times \mathrm{MPE})$ on the sides. Exposures measured on the outside of clothing was substantial (eg, mean 8-hour UVR dose for welders was around 9795 $\mathrm{mJ} / \mathrm{cm}^{2}(3265 \times \mathrm{MPE})$, with mean ambient UVR levels of $16.4 \mathrm{~mJ} / \mathrm{cm}^{2}(5.5 \times \mathrm{MPE})$.

The high ambient and "body" exposures measured in the study by Tenkate \& Collins (3) are not unexpected, however, the levels measured within the welding helmets are of concern considering this represents UVR that has penetrated or by-passed standard protection measures. It has been shown that UVR is able to infiltrate welding helmets by entering from the back and through the sides and top (5). This type of infiltration is likely to occur when welders are in close proximity to each other and the welder is receiving exposure from other welder's emissions. In addition, facial/ocular exposure is also likely to occur when welders flip-up their welding helmet and undertake other work (eg, set-up, handle materials etc). For many welders, the proportion of their welding time per day compared to these other activities has been measured at around 20\% (6), which means that if welders flip-up their helmet and leave it flipped-up, their eyes and faces are directly exposed to ambient UVR and that of nearby welders for a large part of the work day. Wearing safety spectacles underneath welding helmets is a recommended practice (7), however, workers report wearing safety spectacles, particularly underneath welding helmets, is uncomfortable, with visibility impacted due to fogging and sweat $(8,9)$. The use of auto-darkening helmets is one solution to eliminating the practice of flipping-up the helmet.

The Slagor et al paper (1, p451) also states that "we do not know whether welders are more or less exposed to UVR than outdoor workers", with reference made to the average solar UVR exposure of a Danish outdoor worker being $22400 \mathrm{~J} / \mathrm{m}^{2}$ per year (min-max $5400-66900 \mathrm{~J} / \mathrm{m}^{2}$ per year) (10). For comparison, taking the mean 8-hour UVR dose within the welding helmets as $15 \mathrm{~mJ} / \mathrm{cm}^{2}$ (3), this would equate to an annual ocular/facial UVR dose for welders of $37500 \mathrm{~J} / \mathrm{m}^{2}$ (at 5 days/week, 50 weeks/year). Even though this value is weighted for the ACGIH action spectrum, and the value for the Danish outdoor workers is weighted for the erythema spectrum, it provides a reasonable comparison and indicates that welders are likely to receive comparable facial/ocular UVR doses to outdoor workers.

Slagor et al also state that "it is inferred that welders are not exposed to large amounts of UVR during their work life, in spite of the photokeratoconjunctivitis incidents" (1, p451). I would propose that the UVR dosimetry studies described above $(2,3)$, taken together with studies on UVR emissions of welding arcs which show that the MPE for many welding arcs can be exceeded in a matter of seconds (11-13), indicate that welders do 
work in an extreme UVR environment. These studies also suggest that welders are regularly exposed to levels of UVR that exceed the occupational exposure limits at body sites which are thought to be protected (eg, face and eyes) $(2,3)$. When these exposures are further considered in light of the range of eye conditions reported to occur in welders (14-17), the importance of implementing a comprehensive eye safety strategy for welders and all workers in a welding environment is imperative.

\section{References}

1. Slagor RM, La Cour M, Bonde JP. The risk of cataract in relation to metal arc welding. Scan J Work Environ Health. 2016;42(5):447-53. https://doi.org/10.5271/sjweh.3572.

2. Shehade SA, Roberts PJ, Diffey BF, Foulds IS. Photodermatitis due to spot welding. Br J Dermatol. 1987;117:117-9. https:// doi.org/10.1111/j.1365-2133.1987.tb04100.x.

3. Tenkate TD, Collins MJ. Personal ultraviolet radiation exposure of workers in a welding environment. Am Indust Hyg Assoc J. 1997;58:33-8. https://doi.org/10.1080/15428119791013053.

4. ACGIH. Ultraviolet radiation in: TLVs and BEIs. American Conference of Governmental Industrial Hygienists. Cincinnati; 2016. p. 153-8.

5. Tenkate TSD and Collins MJ. Angles of entry of ultraviolet radiation into welding helmets. Am Indust Hyg Assoc J, 1997; 58:54-6. https://doi.org/10.1080/15428119791013099.

6. Tenkate T. Welding arc time and UV exposure: implications for worker safety. J Occup Health Safety-Aust NZ. 2008;24(2):161-6.

7. ANSI Z49.1:2012. Safety in Welding, Cutting, and Allied Processes. American Welding Society: Miami; 2012.

8. Lombardi DA, Verma SK, Brennan MJ, Perry MJ. Factors influencing worker use of personal protective eyewear. Accident Analysis and Prevention. 2009;41:755-62. https:// doi.org/10.1016/j.aap.2009.03.017.

9. Tenkate TD. Optical radiation hazards of welding arcs. Rev Environ Health. 1998;13(3):131-46. https://doi.org/10.1515/ REVEH.1998.13.3.131.
10. Thieden E, Philipsen PA, Heydenreich J, Wulf HC. UV radiation exposure related to age, sex, occupation, and sun behavior based on time-stamped personal dosimeter readings. Arch Dermatol. 2004;140:197-203. https://doi.org/10.1001/ archderm.140.2.197.

11. Gourzoulidis GA, Achtipis A, Topalis FV, Kazasidis ME, Pantelis D, Markoulis A. Artificial optical radiation photobiological hazards in arc welding. Physica Medica. 2016;32:981-6. https://doi.org/10.1016/j.ejmp.2016.07.001.

12. Mariutti G, Matzeu M. Measurement of ultraviolet radiation emitted from welding arcs. Health Physics. 1988;54(5):52932. https://doi.org/10.1097/00004032-198805000-00004.

13. Okuno T. Measurement of ultraviolet radiation from welding arcs. Industrial Health. 1987; 25:147-56. https://doi. org/10.2486/indhealth.25.147.

14. Zlateva V, Toncheva R, Andreev A. Epidemiological studies on occupational eye pathology. Eur. J. Ophthalmol. 1996;6(4):440-5.

15. Lombardi DA, Pannala R, Sorock GS, Wellman H, Courtney TK, Verma S, Smith GS. Welding related occupational eye injuries: a narrative analysis. Injury Prevention. 2005;1:174-9. https://doi.org/10.1136/ip.2004.007088.

16. Tenkate T, Collins MJ. A survey of symptoms and eye safety practices among welders. Clin Exp Optom. 1990;73(3):79-85. https://doi.org/10.1111/j.1444-0938.1990.tb03107.x.

17. Shah CP, Weis E, Lajous M, Shields JA, Shields CL. Intermittent and chronic ultraviolet light exposure and uveal melanoma: a meta-analysis. Opthalmology. 2005;112:1599 607. https://doi.org/10.1016/j.ophtha.2005.04.020.

\author{
Thomas D Tenkate, DrPH \\ Ryerson University \\ 350 Victoria Street \\ Toronto, Ontario, M5B 2K3 \\ Canada \\ [E-mail: thomas.tenkate@ryerson.ca]
}

